\title{
Investigation of hydrological drought using Cumulative Standardized Precipitation Index (SPI 30) in the eastern Mediterranean region (Damascus, Syria)
}

\author{
Boulos Abou Zakhem* and Bassam KattaA \\ Department of Geology, Atomic Energy Commission of Syria (AECS), Damascus, Syria. \\ ${ }^{*}$ Corresponding author. e-mail: cscientific2@aec.org.sy
}

The Eastern Mediterranean region has been exposed to drought episodes, which have been occurring more frequently during the last decades. The objective of the present paper is to study the precipitation regime of the Damascus (Mazzeh) meteoric station by analysing drought characteristics using the Standardized Precipitation Index (SPI) and comparing this with the drought in Cyprus. The cumulative drought concept is proposed to characterize long-term hydrologic drought, which affects the shallow groundwater productivity in terms of quantity and quality. Gamma probability distribution was fitted to the long-term annual precipitation in Damascus from 1918-1919 to 2007-2008 ( $n=90$ years). Generally, a decreasing trend of $17 \%$ to the mean annual rainfall of Damascus and $13 \%$ to the mean annual rainfall of Cyprus was estimated between 1970 and 2000. The SPI identifies three major extended drought periods: (1) 9 years of severe drought (1954-1963) with an average $20 \%$ precipitation deficit per year compared to the mean. (2) 8 years of severe drought (1983-1991) with a $27 \%$ deficit per year on average. (3) 9 years of extreme drought (1993-2002) with a $31 \%$ deficit per year on average. The cumulative standardized precipitation index (SPI 30) demonstrates positive values for the first period and is indicative of having no effect on the global water balance. SPI 30 exhibits sensitive equilibrium with near zero values / a near zero value $( \pm 1.5)$ for the second period. For the third period, however, the SPI 30 decreases below -10 indicating an extreme hydrological drought that has negative consequences on the recent groundwater recharge. It is required to develop and implement a sustainable groundwater management strategy to reduce long-terms drought risks. Generally, the SPI 30 in Cyprus is parallel to that in Damascus with a 3-5 year delay. Thus, the central zone of the Eastern Mediterranean region is facing big challenges and has been suffering from three decades of moderate to severe hydrological drought (SPI $30=-5$ to -10) causing a severe decrease in springs discharges of the region. Therefore, in order to reduce the climate change effects on water resources, it is necessary to adopt a sustainable proactive management plan during the frequent severe droughts.

\section{Introduction}

In the Mediterranean, water scarcity due to drought needs to be investigated with appropriate approaches. These approaches include identifying the priority of relevant drought impacts and then examining the underlying environmental, hydrologic, economic and social causes of these impacts. This process is fundamental to decide on specific mitigation actions that can be taken to reduce

Keywords. Hydrological drought; precipitation; cumulative standardized precipitation index (SPI 30); eastern Mediterranean; Syria. 
short and long-term drought risks. Such actions will differ from one place to another, and have to be adapted to work with the prevailing conditions using simple and practical tools for drought management and improvement. To achieve successful management of droughts, there is a need for better understanding of the characteristics and consequences of those phenomena, which make water scarcity due to drought, very different from those caused by aridity. Drought is a temporary aberration within the natural variability and can be considered as an insidious hazard of nature. Dealing with drought requires the development and implementation of preparedness and emergency measures (MED WS and D WG 2007).

In the Mediterranean, to manage drought, it is necessary to shift from crisis management approaches, where responses and actions are made during the event with no prior planning, to risk management approaches. Risk management is the opposite of crisis management, where a proactive approach is taken well in advance of an expected drought condition, so that the mitigation can reduce drought impacts, and so breathing space and recovery decision are met in a timely, coordinated and effective manner during a drought. However, making the transition from crisis management to risk management to manage droughts, is still difficult in most countries of the region and therefore, much more needs to be done to understand and address the risks associated with drought (Hamdy 2004).

Climate models project increased aridity in the 21st century over most of Africa, southern Europe and the Middle East (Dai 2011). The Mediterranean regions are becoming hotter and drier. The climate change scenarios for 2050 predict a reduction in rainfall between $15 \%$ and $25 \%$ and an increase in temperature between $1.5^{\circ}$ and $2.75^{\circ} \mathrm{C}$. Subsequently, the expected negative impact would be a reduction in water resources both in terms of water availability and water withdrawals (Ragab and Hamdy 2004; IPCC 2007). The Figeh Spring discharge has been assessed with a hydrological runoff model based on an artificial neural network (ANN) approach. The investigations show that spring discharges might face serious problems under changed climatic conditions. The main hydrological modelling results reveal that the mean discharge values decrease by $20 \%$ towards the end of 2050 and by $50 \%$ towards the end of the century (Kayyal 2011; Smiatek et al. 2013).

In the Mediterranean region, regional drought assessment in Cyprus was investigated using SPI (Hajispyrou et al. 2007; Michaelides and Pashiardis 2008; Pashiardis and Michaelides 2008). Drought patterns in the Valencia region (eastern Spain) were studied using monthly precipitation series and the standardized precipitation index (SPI) (Vicente-Serrano et al. 2004). Cancelliere et al. (2005, 2006) contributed to the development of drought forecasting methodologies based on stochastic techniques, with particular reference to the SPI in Italy. The temporal and spatial characteristics of meteorological drought have been investigated to provide a framework for sustainable water resources management in the region of Thessaly, Greece (Loukas and Vasiliades 2004). Drought vulnerability in Turkey has been investigated using SPI. This study implemented multi-natural aspects of drought with respect to the frequency of drought occurrence and its spatial distribution, to identify drought-prone areas and drought vulnerability at multiple-time scales (Turgu 2008).

The study area has been abnormally exposed to extended hydrological droughts during the past three decades, causing a significant decrease of springs discharge due to severe shortage of rainfall. Therefore, the present paper aims to study the precipitation regime of the Damascus meteoric station, its drought characteristics using SPI, and comparing this with the drought in Cyprus, representing the central zone of eastern Mediterranean region. Furthermore, the cumulative drought concept is proposed to characterize the long-term hydrologic drought, which affects the shallow groundwater productivity in terms of quantity and quality.

\subsection{Drought definition}

In general terms, drought can be defined as a deficiency of rainfall with respect to the normal, related to seasons or longer periods, causing an insufficiency of water to meet human and environmental demands (activities and ecosystem functions). It is considered as a normal, recurrent feature of climate. It occurs in virtually all climatic zones and is temporary, while aridity is a permanent feature of climate. Drought is a relative, rather than an absolute condition that must be defined for each region and location. It is also related to the time (i.e., principal season of occurrence). Droughts can vary in intensity, duration and spatial extent. Droughts have been grouped by type as follows (Wilhite and Glantz 1987; Hamdy 2004; MED WS and D WG 2007):

\subsubsection{Meteorological drought}

These are expressed solely on the basis of the degree of dryness (often in comparison to some 'normal' or average amount) and are usually measured for long-term records. 


\subsubsection{Agricultural drought}

It is specifically concerned with the effects of water shortages on crops, grasses and other forages. Therefore, agricultural drought is most closely associated with deficiencies that occur in soil moisture and leading to losses in yield. Agriculture is usually the first sector to experience the devastating effects of drought.

\subsubsection{Hydrological droughts}

These are more concerned with the effects of periods of precipitation shortfalls on surface or subsurface water supply (i.e., stream flow, reservoir and lake levels, groundwater, etc.) rather than with precipitation shortfalls. Hydrological droughts are usually out of phase or lag the occurrence of meteorological and agricultural droughts. Water in hydrologic storage systems (e.g., reservoirs, rivers) is often used for multiple and competing purposes, further complicating the sequence and quantification of impacts.

\subsubsection{Groundwater drought}

This is new concept introduced by Mishra and Singh (2010) which emphasizes on the understanding of complicated hydrogeological processes with respect to the change in dynamics of hydrometeorological variables with changes in land cover.

\subsection{Morphology and climate}

The morphological features of Syria (figure 1a) include a narrow coastal zone, the Lebanon mountain chain in the west that reaches an altitude of $3000 \mathrm{~m}$ in Kerneh Soudah in Lebanon, the Levantine Rift valley with an altitude of $600-700 \mathrm{~m}$ that is represented by the $\mathrm{Al}$ Ghab and Bikaa plains, the eastern Anti-Lebanon mountains, which has the highest altitude of $2814 \mathrm{~m}$ in Harmon Mountain, the Syrian steppe plains (Badieh) with an altitude of 300-500 m, and the Palmyride mountain chains stretching from the Levantine Rift valley to the middle of Syria with an altitude of 1000$2000 \mathrm{~m}$. The mountains act as barriers against the marine air masses coming from across the Mediterranean Sea. However, there are three topographic gaps with altitudes ranging from 600 to $700 \mathrm{~m}$. Homs gap stretches along the Tartous-HomsPalmyra axis where the climatic zone is shifted to the east. The Bab al Hawa gap is located in the northwest, and the Banias gap in the southwest (figure 1a).
The climate in Syria is affected by several air masses (Eaid 2000) as follows:

- Continental polar air mass originating from Siberia that is cold and dry, especially when it is coming from northeast.

- Maritime tropical air masses transported from the Atlantic Ocean and west Europe across the Mediterranean Sea that causes high precipitation during wintertime.

- Continental tropical air masses from North Africa that becomes more humid across the Mediterranean Sea and produces moderate rainfall in Syria.

- Air masses coming from the Red Sea and Sinai desert, characterized by hot and dry winds. It causes sand storms with small amounts of rainfall during springtime and is called the 'Khamsin depression' (El-Asrag 2005).

- Continental tropical air masses from India producing hot and dry winds during the summer season.

Syria is divided into several climatic zones:

- a humid zone in the mountain range and near the coast, where the precipitation is above $800 \mathrm{~mm} /$ year,

- a sub-humid zone towards the east and southeast, where the precipitation is between 400 and $600 \mathrm{~mm} /$ year,

- a semi-arid zone with rainfall between 200 and $400 \mathrm{~mm} /$ year; and

- finally an arid zone in the southeast with rainfall of about $100 \mathrm{~mm} /$ year (figure 1b).

The precipitation period in Syria extends from November to March, and the dry and hot summer period lasts from June to September. The springtime (end of March until June) is characterized by a warm climate with short local rainfall.

\section{Materials and methods}

\subsection{Precipitation characteristics of Damascus (Mazzeh)}

The study is based on the annual precipitation data of Damascus (Mazzeh) meteorological station, available from 1918-1919 to 2007-2008 (90 years). The hydrological cycle, starting from the beginning of September to the end of August of an $n=12$ months time scale, was the accumulation window for statistical distribution fitting and the SPI estimation. An overview of the precipitation characteristics of Damascus (Mazzeh), frequency and probability distribution such as gamma distribution fitting are presented in the first section. 

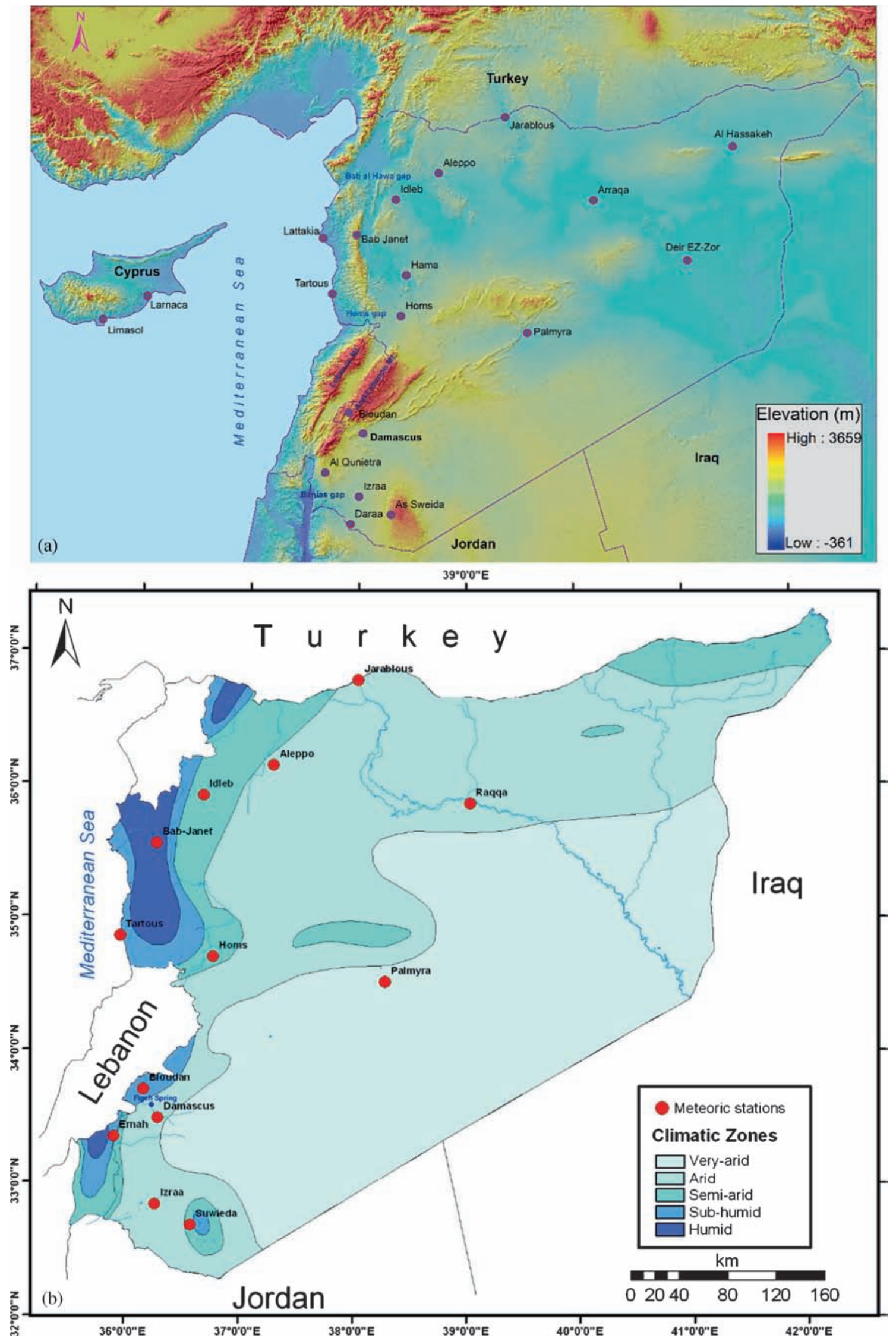

Figure 1. (a) Relief map and (b) climatic zones of Syria (modified from United Nation 1982). 
The application of SPI and the identification of the drought periods are presented in the second section. The deficit of the drought year is estimated by the difference between precipitation and the mean, divided by the mean as follows: (Def. $\%=$ $m-P i / m) \times 100)$ where, $m$ is the mean and $P i$ is the precipitation of the drought year $i$. SPI 30 is proposed in the third section to describe and analyze the not introduced 'integrated standardized hydrological drought'. The precipitation patterns are then compared with those of Cyprus, representing the central zone of Eastern Mediterranean region.

\subsection{Standardized Precipitation Index (SPI) (McKee et al. 1993)}

The SPI is an index based on the probability of precipitation for any time period. It can be computed for different time scales, which allows it to be useful for both short-term agricultural and longterm hydrological applications. These time scales reflect the impact of drought on the availability of different water resources. Soil moisture conditions respond to precipitation anomalies on a relatively short scale, while groundwater, sub-surface flow, and reservoir storage reflect longer-term precipitation anomalies (Hamdy 2004; MED WS and D WG 2007). The SPI can provide early warning of drought and help assess drought severity. Because of its standardization, it is particularly suited to compare drought conditions among different time periods, and regions with different climatic conditions (Bonaccorso et al. 2003; Hamdy 2004). Due to its intrinsic probabilistic nature, SPI is the ideal candidate for carrying out drought risk analysis (Guttman 1999). It has widespread applications (McKee et al. 1995; Heim 2000; Rossi and Cancelliere 2002; Hayes et al. 2005).

The SPI calculation for any location is based on the long-term precipitation record for a desired period. This long-term record is fitted to a probability distribution such as gamma distribution, which is then transformed to a normal distribution so that the mean SPI for the location and desired period, is zero (Edwards and McKee 1997). Positive SPI values indicate greater than median precipitation, and negative values indicate less than median precipitation. Because the SPI is normalized, wetter and drier climates can be represented in the same way, and thus, wet periods can also be monitored using the SPI.

Computation of the SPI involves fitting a gamma probability density function to a given frequency distribution of precipitation. The parameters $\alpha$ and $\beta$ of the gamma probability density function are estimated for the precipitation time series $(3,6$,
12,24 and 48 months). The gamma distribution is defined by its probability density function:

$$
g(P)=\frac{1}{\beta^{\alpha} \Gamma(\alpha)} p^{\alpha-1} e^{-P / \beta} \quad \text { for } P>0
$$

where $\alpha$ is the shape parameter $(\alpha>0), \beta$ is the scale parameter $(\beta>0), P$ is the precipitation amount $(P>0)$ and $\Gamma(\alpha)$ is the gamma function of $\alpha$. Maximum likelihood solutions are used for optimal estimations of $\alpha$ and $\beta$ (Thom 1966; Edwards and McKee 1997; Guttman 1999). The mean $(m)$ and standard deviation $(\sigma)$ of the precipitation time series can be calculated based on the shape and scale parameters where $m=\alpha \beta$ and $\sigma=\beta \sqrt{\alpha}$, respectively.

The cumulative probability $G(P)$ of an observed precipitation occurring for a given month and time scale is given by:

$$
G(P)=\frac{1}{\beta^{\alpha} \Gamma(\alpha)} \int_{0}^{p} p^{\alpha-1} e^{-P / \beta} d p .
$$

Since this equation is not valid for zero precipitation $(P=0)$, the complete cumulative probability distribution, including zero, is expressed as follows:

$$
H(P)=q+(1-q) G(P)
$$

where $q$ and $1-q$ are the probabilities of zero $(P=0)$ and non-zero $(P \neq 0)$ precipitations, respectively. Generally, the time series of monthly precipitation can include zero precipitation. In this study, which includes large time scales (e.g., 12 months) the probability of null precipitation was zero. $S T A$ TISTICA V6 and XLSTAT V7.5 softwares were used for statistical analyses.

SPI is defined by the following equation (McKee et al. 1993; Vicente-Serrano et al. 2004; Saigh 2005):

$$
\mathrm{SPI}=\frac{P i-m}{\sigma}
$$

where $P i$ is the precipitation of year $i, m$ is the long-term mean annual precipitation and $\sigma$ is the standard deviation. The SPI is a dimensionless index where negative values indicate drought and positive values indicate wet conditions. Drought intensity, magnitude and duration as well as the climatic classification with the probabilities of occurrence and $\Delta P \%$, can be determined, using the SPI (Cancelliere et al. 2006) (table 1).

\subsection{Cumulative standardized precipitation index} (SPI 30)

Hydrological drought refers to deficiencies in surface and subsurface water supplies. This drought 
Table 1. Wet and drought period classification according to SPI index.

\begin{tabular}{lllc}
\hline Index value & \multicolumn{1}{c}{ Class } & Probability & $\Delta P(\%)$ \\
\hline $2 \leq \mathrm{SPI}$ & Extremely wet & $0.977-1.000$ & 2.3 \\
$1.5 \leq \mathrm{SPI}<2$ & Very wet & $0.933-0.977$ & 4.4 \\
$1 \leq \mathrm{SPI}<1.5$ & Moderately wet & $0.841-0.933$ & 9.2 \\
$-1 \leq \mathrm{SPI}<1$ & Near normal & $0.159-0.841$ & 68.3 \\
$-1.5 \leq \mathrm{SPI}<-1$ & Moderate drought & $0.067-0.159$ & 9.2 \\
$-2 \leq \mathrm{SPI}<-1.5$ & Severe drought & $0.023-0.067$ & 4.4 \\
$\mathrm{SPI}<-2$ & Extreme drought & $0.000-0.023$ & 2.3 \\
\hline
\end{tabular}

Table 2. Drought severity classes with occurrence probability of SPI and SPI 30.

\begin{tabular}{llcc}
\hline SPI & Drought classes & Probability & SPI 30 \\
\hline 0 to -1 & Normal & $50-15.87 \%$ & 0 to -5 \\
-1 to -2 & Moderate to severe & $15.9-2.28 \%$ & -5 to -10 \\
-2 to -3 & Extreme & $2.28-0.14 \%$ & -10 to -15 \\
\hline
\end{tabular}

can directly be measured as stream, river flow and as lake, reservoir and groundwater levels. Because there is a time lag between the time of rain falling and its appearance in streams, rivers, lakes and reservoirs, hydrological measurements are not the earliest indicators of drought. Shallow groundwater and karstic spring systems are generally very sensitive and vulnerable to extended and severe droughts. Overexploitation induces drawdown and deterioration of groundwater quality (Wilhite and Glantz 1987; Hamdy 2004; MED WS and D WG 2007).

SPI 30 is proposed to describe and analyze the hydrological drought and its possible effect on groundwater reservoir. It is computed by integrated standardized precipitation index for the past 30 years as follows (Abou Zakhem and Kattaa 2015):

$$
\text { SPI } 30=\sum_{i=n-30}^{i=n} \frac{P i-m}{\sigma}
$$

where $n$ is the total number of years for which the SPI is being calculated.

The probabilistic characteristics of SPI (McKee et al. 1993), allow us to classify several hydrologic drought categories. Here, we suggested a simple additive classification where:

- SPI 30 between 0 and -5 corresponds to normal hydrologic drought, indicating that groundwater recharge is in equilibrium with around average precipitation.

- SPI 30 between -5 and -10 indicates moderate to severe hydrologic drought, producing severe decrease of groundwater recharge. It requires an adapted crisis management for groundwater protection.
- SPI 30 between -10 and -15 demonstrates extreme hydrologic drought, corresponding to an extreme decline in groundwater recharge. It necessitates the development and implementation of sustainable groundwater management to reduce long-terms drought risks.

The severity classes of hydrologic drought SPI 30 $(0,-5,-10$, and -15) are based on the consequences of the drought on groundwater resources due to low rainfall. The SPI (12 months) is computed by the method of McKee et al. (1993) and is directly related to occurrence probability of drought category. To calculate the occurrence probability of SPI 30, the SPI (360 months) is computed by the same method, which is identical to SPI probability. The drought severity classes of SPI 30 are matched with SPI categories as shown in table 2 .

\section{Results and discussion}

\subsection{Damascus precipitation characteristics}

The long-term mean annual precipitation (90 years) is $m=202 \mathrm{~mm}$, the coefficient of variation $\mathrm{CV}=0.34$. The observed minimum annual precipitation was $60 \mathrm{~mm}$ in 1998/99 and the maximum $360 \mathrm{~mm}$ in $1952 / 53$. The frequency distribution of the annual precipitation of Damascus from 19181919 to $2007-2008$ ( $n=90$ years) indicates that the time series can fit to a gamma distribution. The shape parameter $\alpha$ is 7.7834 and the scale parameter $\beta$ is 25.9213. Kolmogorov-Smirnov $d=$ 0.07053 , and $\chi^{2}$ test $=6.41907, d f=2$ (adjusted), $p=0.04038$ (figure 2a). Based on the shape and scale parameters, mean and standard deviation values were 201.7558 and 72.3172 , respectively. The 


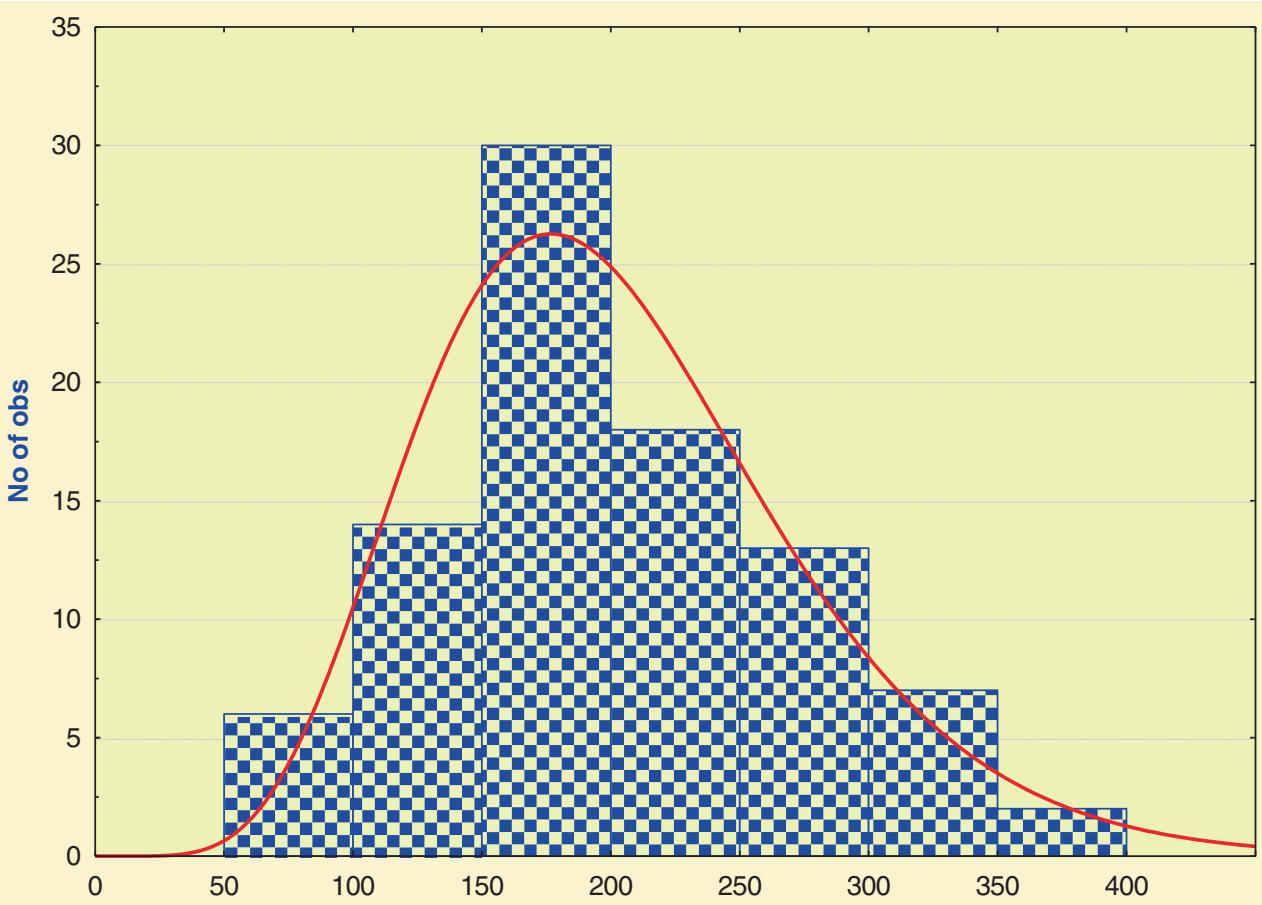

(a)

Precipitation $\mathrm{mm} / \mathrm{y}$

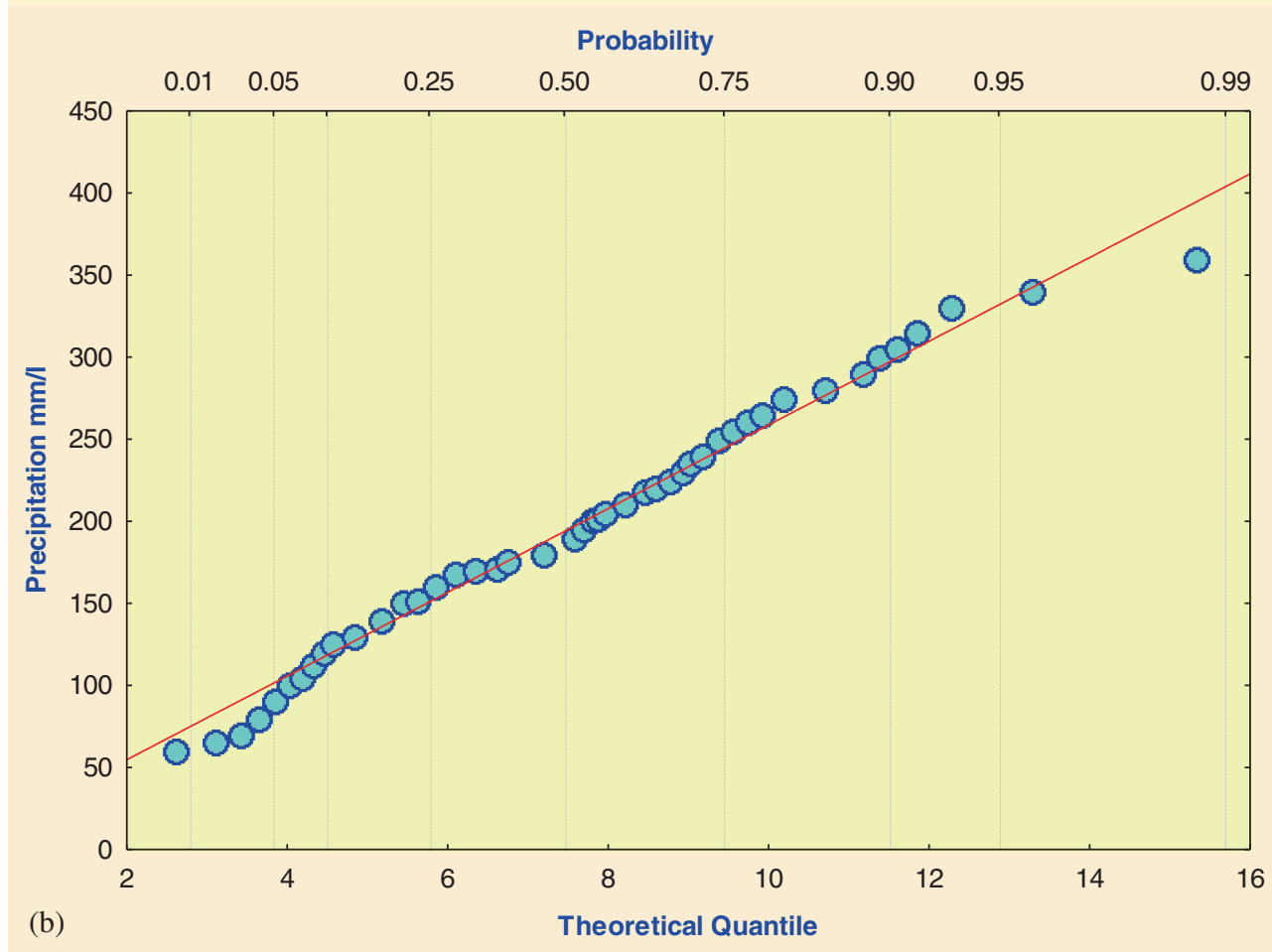

Figure 2. Annual precipitation in Damascus (1918-1919 to 2007-2008, $n=90$ years): (a) Fitted to gamma distribution $\left(P=90^{*} 50^{*}\right.$ gamma $\left.(\mathrm{x} / 25.92,7.78) / 25.92\right)$ and $(\mathbf{b})$ theoretical quantile and gamma probability plot $\left(P=3.7+25.5^{*} \mathrm{x}\right)$.

annual precipitation, probability and theoretical quantile are presented in figure 2(b) which demonstrates that the long-term annual precipitation has gamma probability distribution.

Figure 3(a) shows that the annual precipitation in Damascus is decreasing gradually. The mean annual rainfall in the period 1941-1970 was
$217 \mathrm{~mm}$, in the period $1951-1980$ it was about $208 \mathrm{~mm}$ and during the period 1961-1990 it was $201 \mathrm{~mm}$, while during the period 1971-2000 it was only $180 \mathrm{~mm}$. Generally, a decreasing trend of about $37 \mathrm{~mm}(17 \%)$ to the mean annual rainfall of Damascus meteorological station was estimated between 1970 and 2000. A similar decreasing trend 

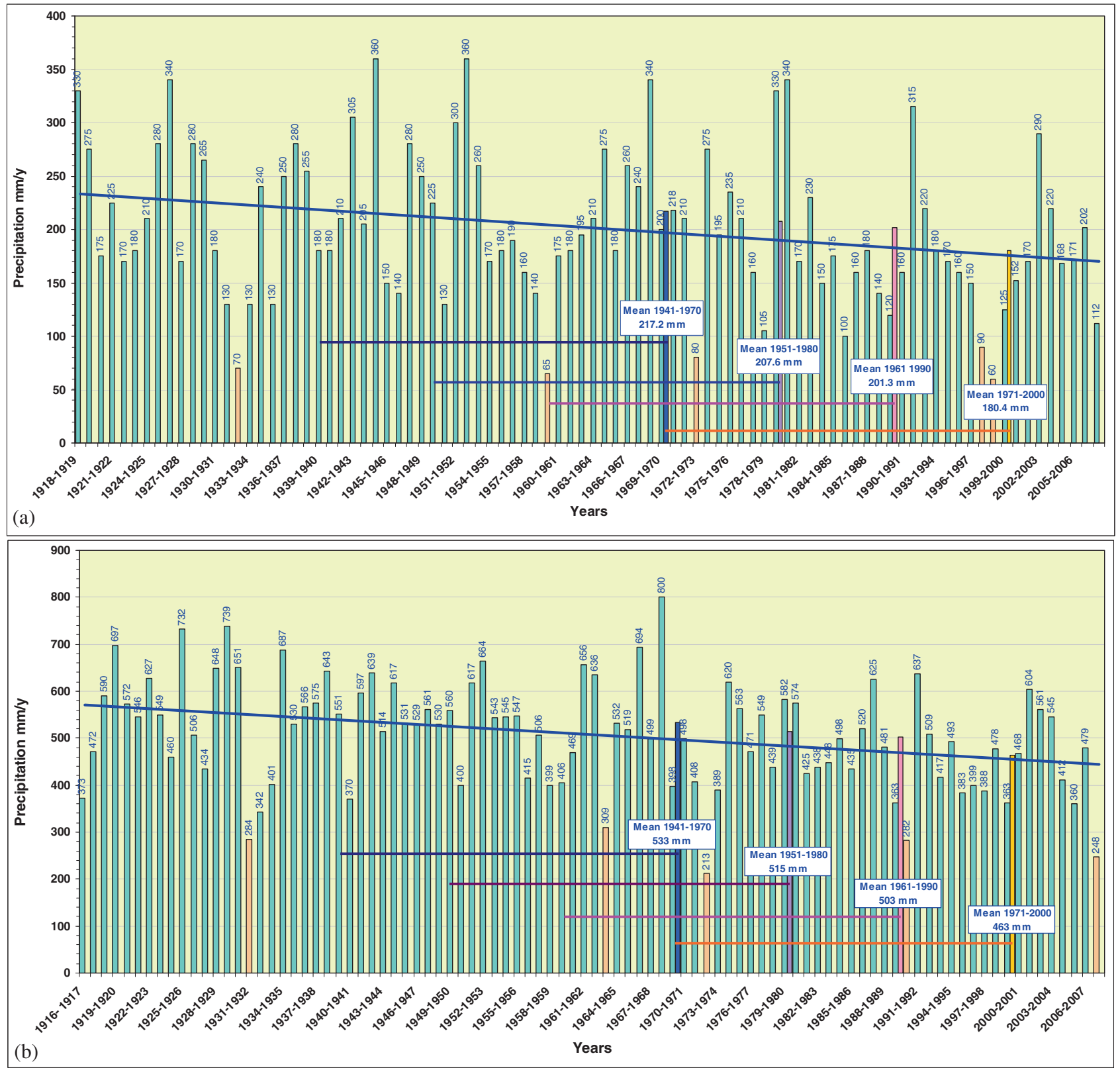

Figure 3. Annual precipitation: (a) Damascus (1918-2008) and (b) in Cyprus (1916-2008).

is shown for the time series of the annual area average precipitation in Cyprus (1916-2008) where the mean annual rainfall in the period 1941-1970 was $533 \mathrm{~mm}$, while during the period 1971-2000, it was only $463 \mathrm{~mm}$ with a decreasing trend of about $70 \mathrm{~mm}$ (13\%) (figure 3b) (Hajispyrou et al. 2007; Pashiardis and Michaelides 2008).

A comparison of the mean precipitation in Damascus and Cyprus over past 30 years, computed for years 1970, 1980, 1990 and 2000 reveals that the decline in precipitation in Damascus is around $-1.2 \mathrm{~mm}$ per year while in Cyprus, it is around $-2.4 \mathrm{~mm}$ per year (figure 4). The relationship between the mean precipitation over the past 30 years in Damascus and Cyprus is linear with a high correlation coefficient $\left(R^{2}=1\right)$. A decline of $17 \%$ from the mean annual rainfall in Damascus corresponds to a decrease of $13 \%$ from the mean annual rainfall in Cyprus. Thus, the climate of these regions is representative and typical of the eastern Mediterranean region which is vulnerable and prone to severe droughts, as was experienced during the last decades of 20th century.

\subsection{Standardized precipitation index (SPI)}

The long-term variation of precipitation shows high irregularity, and during the last three decades 


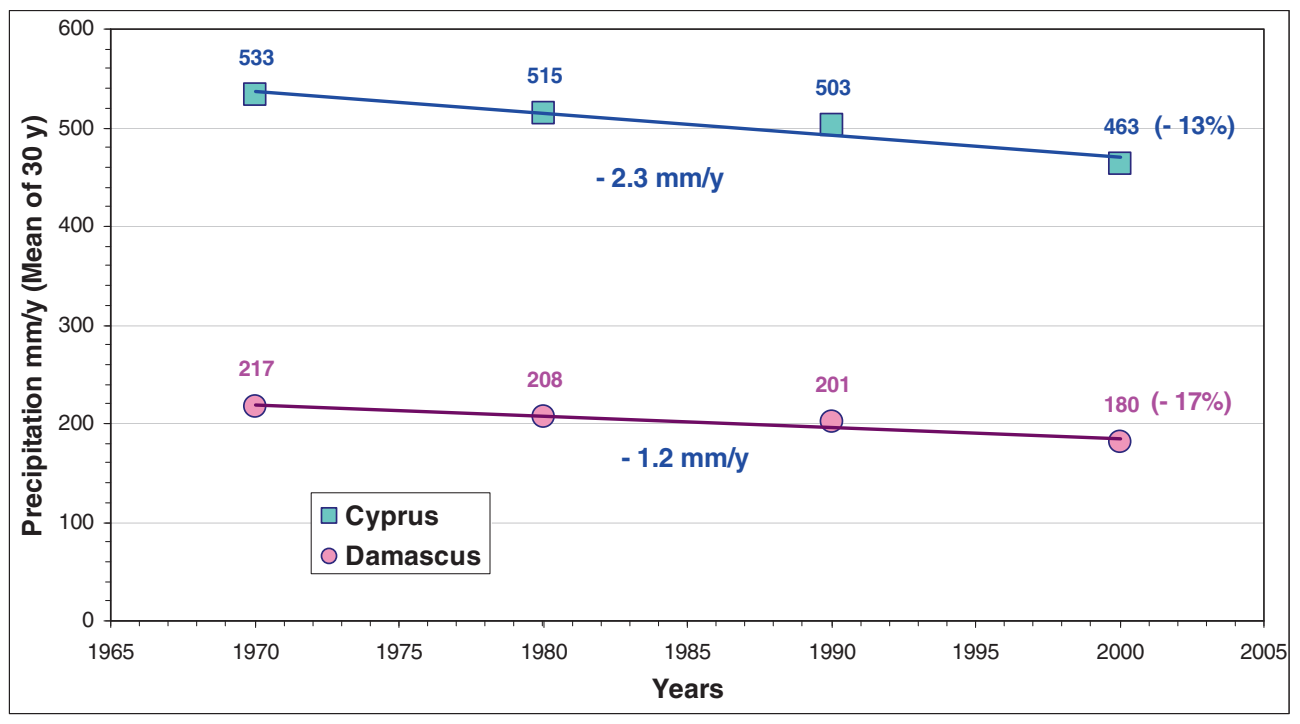

Figure 4. Mean precipitation of 30 yrs in Damascus and in Cyprus.

of the study period, a trend towards drought is observed (figure 3). The irregularity can be expressed by the standardized precipitation index (SPI), defined by McKee et al. (1993).

The frequency of drought events in Damascus, with a lower than average precipitation of varying severity, duration and scale has been highly variable during the last century as observed in table 3 and figure 5, which shows the actual average annual rainfall during the periods 1918-1919 to 2007-2008. Over the first half of the last century, drought recurrence was observed between 2 to 4 years. Post 1950 however, the droughts have intensified and become more frequent, occurring for as much as 8 to 9 consecutive years with the rainfall, lower than average. Between 1954 and 1963, a severe drought that extended for 9 years had the maximum deficit reaching $68 \%$ in $1959-1960$ with a $20 \%$ deficit per year on average. Two consecutive drought periods were extremely severe, extending to almost the entire forth quarter of the last century. The first drought period extended for 8 years between 1983 and 1991 with a 27\% deficit per year on average. Subsequently another period of drought extending for 9 years between 1993 and 2002 had a maximum deficit reaching $70 \%$ in $1998-1999$ with a $31 \%$ deficit per year on average.

The SPI for precipitation in Damascus is shown in figure 5 together with 8-year moving average that are useful indicators of inter-annual changes in precipitation. The 8-year moving average of SPI was estimated by first calculating the moving average of precipitation and afterwards normalizing it to calculate the SPI. Furthermore, figure 5 includes the polynomial line (3rd degree) of the 8-year moving average that characterizes the long-term trend in precipitation. The moving averages clearly indicate a decline in precipitation and thus an increase of drought since the early 1980s. Furthermore, over the last 30 years of the study, 8 wet years and 22 drought years can be identified. The mean annual rainfall in the wet period 1918-1978 (60 yrs) was around $214 \mathrm{~mm}$, while in the drought period 19782008 (30 years) it was around $177 \mathrm{~mm}$. However, during the last decade of the study, i.e., between 1998 and 2008 it was only $167 \mathrm{~mm}$. Generally, depending on the long-term mean annual precipitation, a significant decreasing trend of about $17 \%$ occurred during the last 30 years of the study. A similar decreasing trend of the mean annual rainfall was detected in Cyprus for the same period of the 20th century. This drought could be seen as a consequence of the global warming (Pashiardis and Michaelides 2008; Abou Zakhem and Hafez 2010).

The annual precipitation was fitted to gamma distribution and then converted to an SPI value with a mean of zero and variance of one. Figure 6 illustrates the conversion method, where on the left side, the empirical cumulative probability distribution of annual precipitation is presented. On the right side of the figure, using the same cumulative probability scale, the standard normalized annual precipitation (or the SPI value) is denoted on the $\mathrm{X}$ axis. Hence, this figure can be used to transform the annual precipitation to the equivalent SPI (Edwards and McKee 1997; VicenteSerrano et al. 2004; Turgu 2008). For example, to find the SPI value corresponding to $240 \mathrm{~mm}$ of precipitation, locate 240 on the $\mathrm{X}$ axis in the graph on the left and go vertically up until the cumulative probability distribution curve is intersected. Then, move horizontally (maintaining equal cumulative probability) to the graph on the right. 
Table 3. Meteorological drought events in Damascus (1918-2008).

\begin{tabular}{|c|c|c|c|c|c|}
\hline No. & Years & $\begin{array}{l}\text { Precipitation } \\
\quad(\mathrm{mm})\end{array}$ & $\begin{array}{c}\text { Average } \\
(\%)\end{array}$ & $\begin{array}{l}\text { Deficit } \\
(\%)\end{array}$ & Remarks \\
\hline 1 & 1920-1921 & 175 & 87 & 13 & One year drought \\
\hline \multirow[t]{2}{*}{2} & $1922-1923$ & 170 & 84 & 16 & \multirow{2}{*}{$\begin{array}{c}\text { Two years drought } \\
13.5 \% / \text { yr deficit }\end{array}$} \\
\hline & 1923-1924 & 180 & 89 & 11 & \\
\hline 3 & $1927-1928$ & 170 & 84 & 16 & One year drought \\
\hline \multirow[t]{4}{*}{4} & 1930-1931 & 180 & 89 & 11 & \multirow{4}{*}{$\begin{array}{c}\text { Four years drought } \\
37 \% / \text { yr deficit }\end{array}$} \\
\hline & 1931-1932 & 130 & 64 & 36 & \\
\hline & 1932-1933 & 70 & 35 & 65 & \\
\hline & 1933-1934 & 130 & 64 & 36 & \\
\hline 5 & 1935-1936 & 130 & 64 & 36 & One year drought \\
\hline \multirow[t]{2}{*}{6} & 1939-1940 & 180 & 89 & 11 & \multirow{2}{*}{$\begin{array}{c}\text { Two years drought } \\
11 \% / y r \text { deficit }\end{array}$} \\
\hline & 1940-1941 & 180 & 89 & 11 & \\
\hline \multirow[t]{2}{*}{7} & 1945-1946 & 150 & 74 & 26 & \multirow{2}{*}{$\begin{array}{c}\text { Two years drought } \\
28.5 \% / \text { yr deficit }\end{array}$} \\
\hline & 1946-1947 & 140 & 69 & 31 & \\
\hline 8 & 1950-1951 & 130 & 64 & 36 & One year drought \\
\hline \multirow[t]{9}{*}{9} & $1954-1955$ & 170 & 84 & 16 & \multirow{9}{*}{$\begin{array}{l}9 \text { years drought } \\
20 \% / \text { yr deficit }\end{array}$} \\
\hline & 1955-1956 & 180 & 89 & 11 & \\
\hline & 1956-1957 & 190 & 94 & 6 & \\
\hline & $1957-1958$ & 160 & 79 & 21 & \\
\hline & 1958-1959 & 140 & 69 & 31 & \\
\hline & 1959-1960 & 65 & 32 & 68 & \\
\hline & 1960-1961 & 175 & 87 & 13 & \\
\hline & 1961-1962 & 180 & 89 & 11 & \\
\hline & $1962-1963$ & 195 & 97 & 3 & \\
\hline 10 & 1965-1966 & 180 & 89 & 11 & One year drought \\
\hline 11 & 1969-1970 & 200 & 99 & 1 & One year drought \\
\hline 12 & $1972-1973$ & 80 & 40 & 60 & One year drought \\
\hline 13 & $1974-1975$ & 195 & 97 & 3 & One year drought \\
\hline \multirow[t]{2}{*}{14} & 1977-1978 & 160 & 79 & 21 & \multirow{2}{*}{$\begin{array}{c}\text { Two years drought } \\
34.5 \% / y r \text { deficit }\end{array}$} \\
\hline & 1978-1979 & 105 & 52 & 48 & \\
\hline 15 & 1981-1982 & 170 & 84 & 16 & One year drought \\
\hline \multirow[t]{8}{*}{16} & 1983-1984 & 150 & 74 & 26 & \multirow{8}{*}{$\begin{array}{l}8 \text { years drought } \\
27 \% / \text { yr deficit }\end{array}$} \\
\hline & 1984-1985 & 175 & 87 & 13 & \\
\hline & 1985-1986 & 100 & 50 & 50 & \\
\hline & 1986-1987 & 160 & 79 & 21 & \\
\hline & 1987-1988 & 180 & 89 & 11 & \\
\hline & 1988-1989 & 140 & 69 & 31 & \\
\hline & 1989-1990 & 120 & 59 & 41 & \\
\hline & 1990-1991 & 160 & 79 & 21 & \\
\hline
\end{tabular}


Table 3. (Continued.)

\begin{tabular}{|c|c|c|c|c|c|}
\hline No. & Years & $\begin{array}{l}\text { Precipitation } \\
(\mathrm{mm})\end{array}$ & $\begin{array}{c}\text { average } \\
(\%)\end{array}$ & $\begin{array}{c}\text { Deficit } \\
(\%)\end{array}$ & Remarks \\
\hline \multirow[t]{9}{*}{17} & 1993-1994 & 180 & 89 & 11 & \multirow{9}{*}{$\begin{array}{l}9 \text { years drought } \\
31 \% / \mathrm{yr} \text { deficit }\end{array}$} \\
\hline & 1994-1995 & 170 & 84 & 16 & \\
\hline & 1995-1996 & 160 & 79 & 21 & \\
\hline & 1996-1997 & 150 & 74 & 26 & \\
\hline & 1997-1998 & 90 & 45 & 55 & \\
\hline & 1998-1999 & 60 & 30 & 70 & \\
\hline & 1999-2000 & 125 & 62 & 38 & \\
\hline & 2000-2001 & 152 & 75 & 25 & \\
\hline & 2001-2002 & 170 & 84 & 16 & \\
\hline \multirow[t]{2}{*}{18} & $2004-2005$ & 168 & 83 & 17 & Two years drought \\
\hline & 2005-2006 & 171 & 85 & 15 & $16 \% / y r$ deficit \\
\hline 19 & $2007-2008$ & 112 & 56 & 44 & One year drought \\
\hline
\end{tabular}

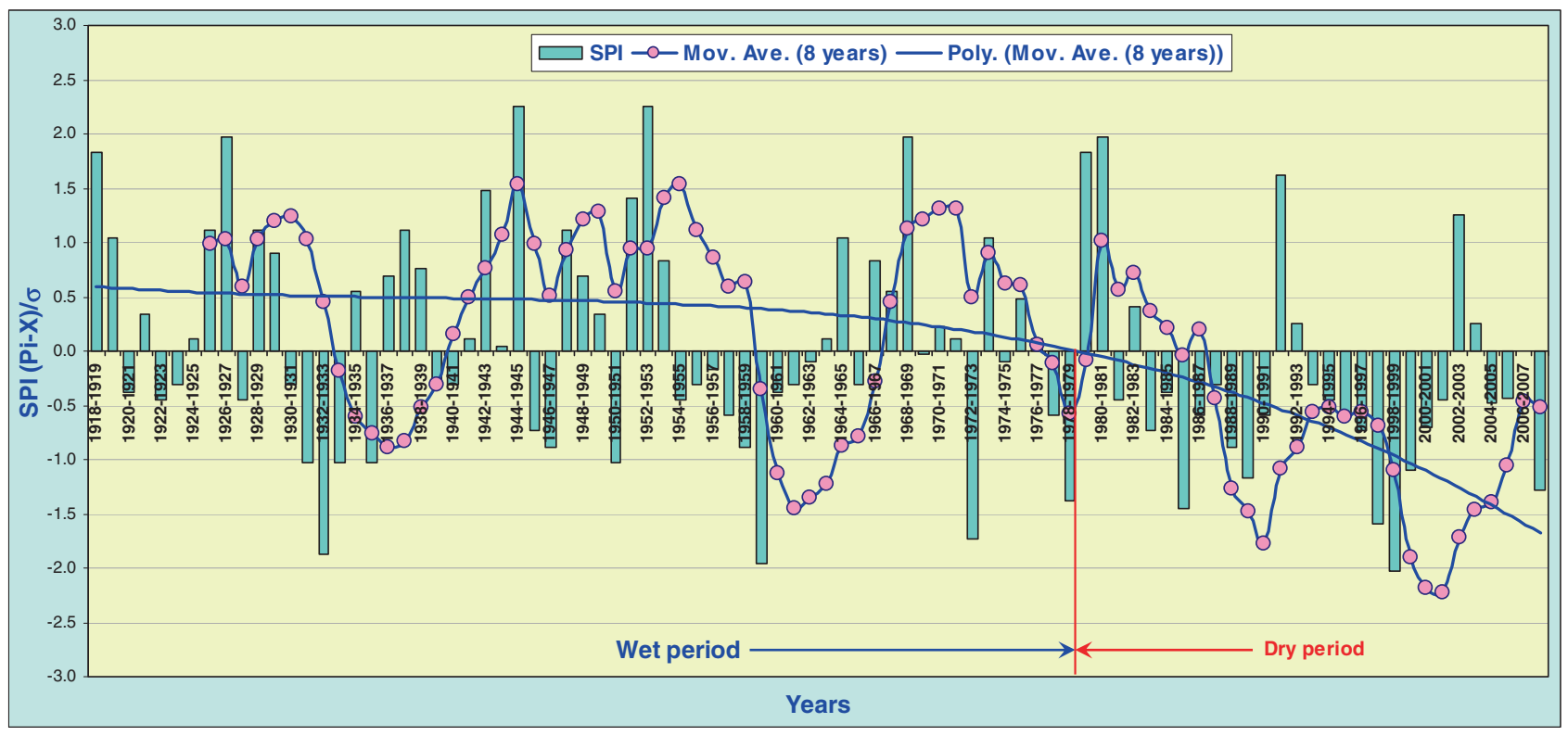

Figure 5. Standardized precipitation index (SPI) in Damascus.

Upon intersection of the standard normal cumulative probability curve, proceed vertically downwards to the $\mathrm{X}$ axis in order to determine the corresponding SPI. In this case, the SPI is 0.51, approximately.

\subsection{Cumulative standardized precipitation index (SPI 30)}

Hydrological drought refers to deficiencies in surface and subsurface water supplies. This drought can directly be measured as stream, river flow and as lake, reservoir and groundwater levels. Because there is a time lag between the time of precipitation and its appearance in streams, rivers, lakes and reservoirs, hydrological measurements are not the earliest indicators of drought. The sequence of impacts associated with meteorological, agricultural, and hydrological droughts highlights their differences. When drought begins, the first to suffer is usually the agricultural sector, because it is heavily dependant on stored soil water. The surface water (i.e., rivers, reservoirs and lakes) will suffer in parallel or just after the agricultural sector, and the subsurface water (i.e., groundwater) is usually the last to be affected. Although, groundwater 


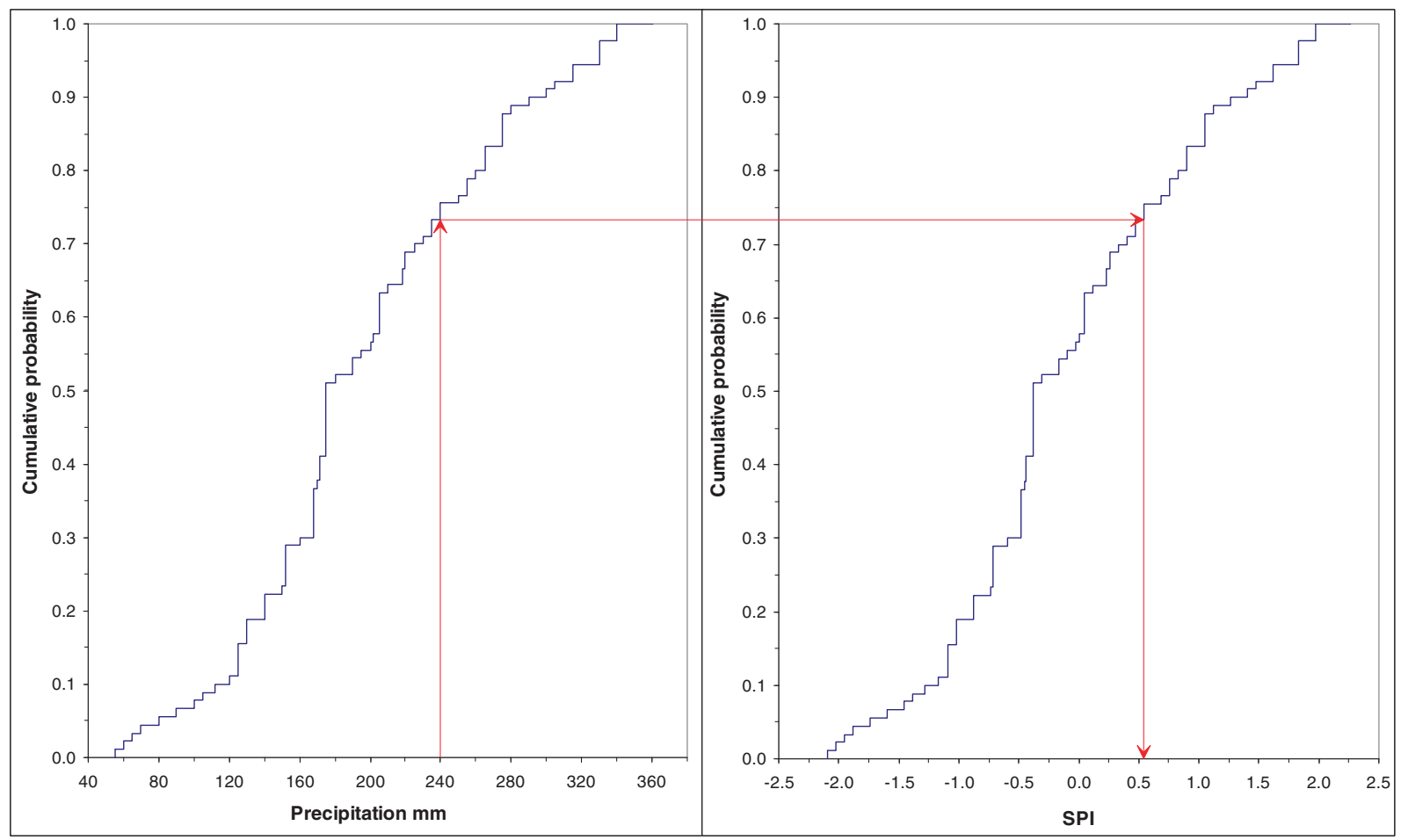

Figure 6. Equi-probability transformation of annual precipitation from cumulative probability distribution to the standard normal distribution (SPI). Arrows indicate the transformation way.

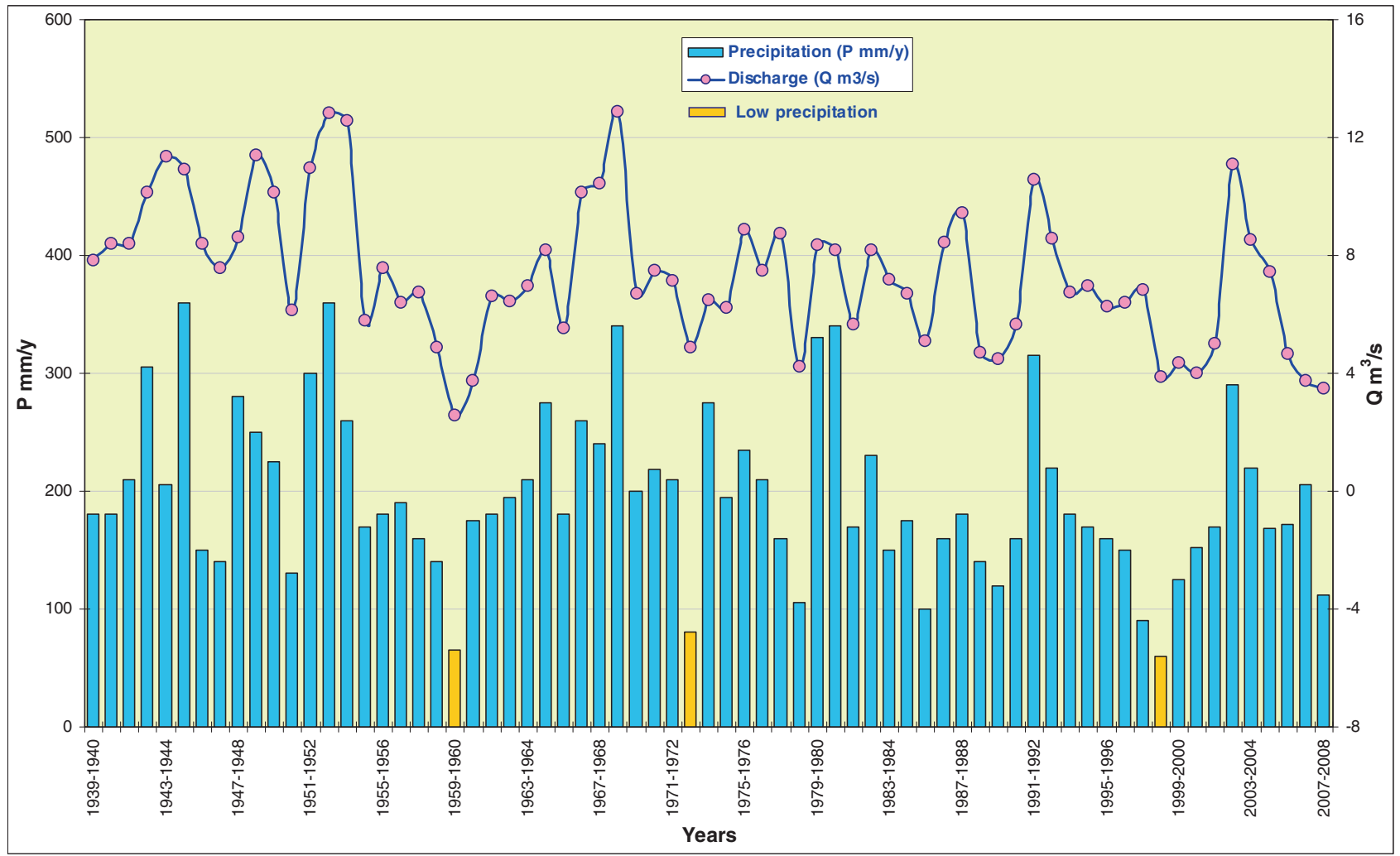

Figure 7. Annual precipitation in Damascus and mean annual discharge of Figeh Spring.

is the last to be affected by drought during its onset, it is the last to experience a return to normal water supply levels. Obviously, the length of the recovery period is a function of the intensity of the drought, its duration, and the quantity of precipitation received following the drought period 
(Wilhite and Glantz 1987; Hamdy 2004; MED WS and D WG 2007).

Shallow groundwater and karstic spring systems are generally very sensitive and vulnerable to the extended and severe drought. On one hand, the groundwater level is affected by drought duration and severity causing a decrease in new recharge of groundwater. On the other hand, the quality of the groundwater can also be affected in negative manner. Therefore, agricultural drought puts the groundwater under stress, causing it to respond by increased demand for irrigation water. Overexploitation induces drawdown and deterioration of groundwater quality.

Based on the completely mixed reservoir model of tritium data, the mean residence time of the
Figeh karstic spring was about 20-40 years before the pumping through boreholes in order to supply Damascus city in 1985 (Kattan 1997; Al-Charideh 2011). Mean annual discharge of Figeh Spring is compared to annual precipitation of Damascus city over 69 years (1939-2008) (figure 7). Discharge line is parallel to precipitation line indicating that groundwater resources are closely related to precipitation. Consecutive drought periods since the eighties of last century caused a decrease in precipitation amount and consequently decline of the groundwater resources (Alammareen 2010; Al-Charideh 2012).

Based on the mean transit time of shallow groundwater and karstic system in Damascus basin, we suggest in our investigation the SPI

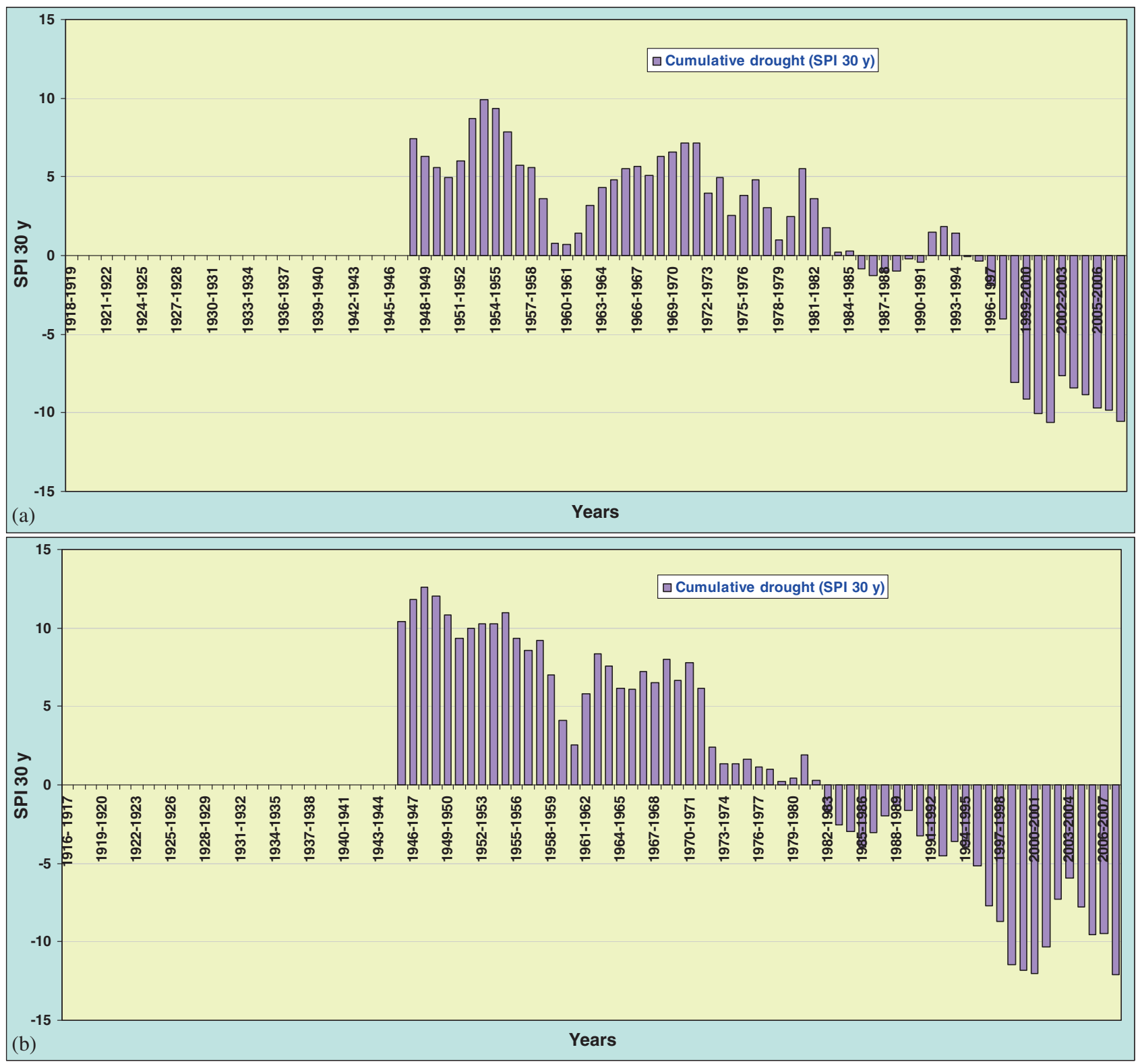

Figure 8. Cumulative standardized precipitation index (SPI 30): (a) in Damascus and (b) in Cyprus. 
30, computed for the past 30 years. It is a simple concept, computed by integrated standardized precipitation index for 30 years, which is the current normal period, as suggested by the World Meteorological Organization and corresponds to the mean transit time of shallow groundwater and karstic spring in the studied region.

The application of SPI 30 on the recorded annual precipitation in Damascus of 90 years (1918-1919 to 2007-2008), illustrates very well, the drought pattern by amplifying its signature to clearly demonstrate the status of the karstic and shallow groundwater recent recharge. Between 1954 and 1963, severe droughts of 9 years had an average of $20 \%$ precipitation deficit. SPI 30 demonstrates positive values indicating that these periods do not affect the global water balance and produces/brings about no sensitive effect on the groundwater reservoirs. This drought was adjusted by a following wet period. The period of 8 years between 1983 and 1991 with a $27 \%$ rainfall deficit on average reduced the SPI 30 to near zero. This period is followed by two very wet years (19921993) and is characterized by positive SPI 30 values. The subsequent period of 9 years between 1993 and 2002, with a high deficit of $31 \%$ on average. During this period, the SPI 30 has rapidly decreased to less than -5 in 1998-1999, indicating severe drought and requiring an adapted crisis management for groundwater. After only 3 years (2000-2001), the SPI 30 decreased below -10 (figure 8a), exhibiting extreme drought that could negatively affect the recent groundwater recharge. It required the development and implementation of sustainable groundwater management to reduce long-terms drought risks.

In 2000, the Directorate of Barada and Awage Basin, in cooperation with the Establishment of Drinking Water Supply of Damascus city initiated a plan for artificial recharge in several sites in the city, to restore groundwater storage capacity and to improve the water quality (Abou Zakhem and Hafez 2012). This planning management is considered as a proactive approach to reduce the impacts of drought. However, the extended extreme drought necessitates more initiatives for groundwater replenishment, protection and water resources development.

The application of SPI 30 on the annual area average precipitation in Cyprus (1916-2008) data from Pashiardis and Michaelides (2008) and Hajispyrou et al. (2007), illustrates a climatic signature almost similar and parallel to the Damascus region. Generally, drought signal in Cyprus is precedent, smoother and deeper than Damascus drought pattern. The drought in Cyprus is characterized by significant marine influence, while in the Damascus region, the climate is predominantly continental (figure 8b). Thus, the central zone of eastern Mediterranean countries is facing big, severe drought challenges since the last decades of the 20th century. Climate change mitigation and water-related disasters need a proactive approach concerning the groundwater resources in a timely, coordinated and effective manner during this extended drought.

\section{Conclusions}

The frequency distribution and the annual precipitation probability demonstrate that the longterm annual precipitation in Damascus has gamma probability distribution. The mean and standard deviation values were 201.7558 and 72.3172 , respectively. The mean annual rainfall during the period 1941-1970 was $217 \mathrm{~mm}$, while in the period 1971-2000 it was only $180 \mathrm{~mm}$. Generally, a decreasing trend of $17 \%$ to the mean annual rainfall of Damascus and 13\% to the mean annual rainfall of Cyprus was estimated between 1970 and 2000. Standardized precipitation index (SPI) identifies three extended major drought periods:

1) 9 years of severe drought (1954-1963) characterized by $20 \%$ precipitation deficit per year on average compared to the mean.

2) 8 years of severe drought (1983-1991) with a $27 \%$ deficit per year on average.

3) 9 years of extreme drought (1993-2002) with a maximum deficit reaching up to $70 \%$ in $1998-$ 1999 and a 31\% deficit per year on average.

Cumulative standardized precipitation index (SPI 30) illustrates very well, the drought pattern and its possible effect on groundwater reservoir. The application of SPI 30 display positive values, indicating that the first period does not affect the global water balance and bears no sensitive effect on groundwater resources. The SPI 30 exhibits a sensitive equilibrium with near zero values $( \pm 1.5)$ for the second period. For the third period, however, the SPI 30 decreases below -10 which is indicative of extreme hydrological drought that can negatively affect the recent groundwater recharge. It warrants the development and implementation of sustainable groundwater management to reduce long-terms drought risks. Generally, the SPI 30 in Cyprus is parallel but preceding to that of Damascus by 3-5 years.

Consequently, the climate of these regions is representative and typical of the eastern Mediterranean region, which is vulnerable and exposed to severe droughts experienced during the last decades of the 20th century that can negatively affect the recent groundwater recharge. Climate 
change mitigation and water-related disasters need a proactive approach concerning the groundwater resources in a timely, coordinated and effective manner during this extended drought.

\section{Acknowledgements}

The authors would like to acknowledge Prof. I Othman, Director General of Atomic Energy Commission of Syria (AECS), for his guidance and support. Thanks are due to Dr. E. Eaid, Director General of Meteorological Department, Damascus, Syria for the valuable meteorological information. The authors would also like to thank Associate Editor of JESS, Prof. Subimal Ghosh and the reviewers for their constructive and valuable comments and suggestions. Finally, thanks to the colleagues in Geology Department (AECS).

\section{References}

Abou Zakhem B and Hafez R 2010 Climatic factors controlling chemical and isotopic characteristics of precipitation in Syria; Hydrol. Process. 24(18) 2641-2654.

Abou Zakhem B and Hafez R 2012 Chemical and isotopic methods for management of artificial recharge in Mazraha station (Damascus Basin, Syria); Hydrol. Process. 26 3712-3724.

Abou Zakhem B and Kattaa B 2015 Cumulative drought effect on Figeh karstic spring discharge (Damascus basin, Syria); Environ. Earth Sci., doi: 10.1007/s12665-015-5013-3.

Alammareen A 2010 Groundwater Exploration in Karst: Examples for Shallow Aquifers using Microgravity Technique in Paderborn-Germany and the Reconnaissance of Deep Aquifers in Catchment of Barada Spring-Syria; Doktor der Naturwissenschaften. der Technischen Universität Berlin, Germany, 318p.

Al-Charideh A 2011 Environmental isotope study of groundwater discharge from the large karst springs in West Syria: A case study of Figeh and Al-sin Springs; Environ. Earth Sci. 63 1-10.

Al-Charideh A 2012 Recharge rate estimation in the mountain karst aquifer system of Figeh Spring, Syria; Environ. Earth Sci. 65 1169-1178.

Bonaccorso B, Bordi I, Cancelliere A, Rossi G and Sutera A 2003 Spatial variability of drought: An analysis of SPI in Sicily; Water Resour. Manag. 17 273-296.

Cancelliere A, Di Mauro G, Bonaccorso B and Rossi G 2005 Stochastic forecasting of standardized precipitation index; In: Proceedings of XXXI IAHR Congress on Water Engineering for the Future: Choice and Challenges, Seoul, Korea, 11-16 September 2005, pp. 3252-3260.

Cancelliere A, Bonaccorso B and Di Mauro G 2006 A nonparametric approach for drought forecasting through the standardized precipitation index; Giornata di Studio: Metodi Statistici e Matematici per l'Analisi delle Serie Idrologiche- Viterbo.

Dai A 2011 Drought under global warming: A review; Wiley Interdisciplinary Reviews; Climate Change 2(1) 45-65, doi: $10.1002 /$ wcc. 81 .
Eaid E 2000 Meteorological Conditions in Mediterranean Basin; General Meteorological Department, Damascus, Syria, 41p.

Edwards D C and McKee T B 1997 Characteristics of 20th century drought in the United States at multiple time scales; Climatology Report Number 97-2; Colorado State University, Fort Collins, Colorado.

El-Asrag A M 2005 Effect of synoptic and climatic situations on fractionation of stable isotopes in rainwater over Egypt and east Mediterranean; IAEA-TECDOC-1453, pp. $51-73$.

Hajispyrou E, Pashardes P, Photiou C, Rostan di N and Tsiourtis N X 2007 Application of the drought management guidelines in Cyprus [Part 2. Examples of application]; In: Drought management guidelines technical annex (eds) Iglesias A, Moneo M and LópezFrancos A, Zaragoza: CIHEAM/EC MEDA Water, pp. 215-244 (Options Méditerranéennes: Série B. Etudes et Recherches n. 58).

Hamdy A 2004 Drought preparedness and mitigation in the Mediterranean region; In: Water Management for Drought Mitigation in the Mediterranean, Centre International de Hautes Etudes Agronomiques Méditerranéennes (CIHEAM), Options Méditerranéennes, Série B, N. 47, p. 328.

Hayes M J, Svoboda M, Le Comte D, Redmond K T and Pasteris P 2005 Drought monitoring: New tools for the 21st century; In: Drought and water crisis (ed.) Wilhite D A, Taylor and Francis, Boca Raton, Florida.

Heim R R 2000 Drought indices: A review; In: Drought: A Global Assessment (ed.) Wilhite D A, Routledge, London and New York.

Guttman N B 1999 Accepting the standardized precipitation index: A calculating algorithm; J. Amer. Water Resour. Assoc. 35(2) 311-323.

IPCC 2007 Regional Climate Projections. Climate Change 2007: The Physical Science Basis; Contribution to Working Group I and to AR4 (Fourth Assessment Report of the Intergovernmental Panel on Climate Change) (eds) Solomon S, Qin D, Manning M, Chen Z, Marquis M, Averyt K B, Tignor $\mathrm{M}$ and Miller $\mathrm{H}$ L, Cambridge University Press, Cambridge, UK, pp. 847-940.

Kattan Z 1997 Environmental isotope study of the major karst springs in Damascus limestone aquifer systems: Case of the Figeh and Barada Springs; J. Hydrol. 193 161-182.

Kayyal M 2011 Climate Change and Utilities DAWSSA Case Study; ACWUA, Best Practices Conference, 7-8 December 2011, Sharm el Sheikh, Egypt.

Loukas A and Vasiliades L 2004 Probabilistic analysis of drought spatiotemporal characteristics in Thessaly region, Greece; Natural Hazards and Earth Syst. Sci. 4 719-731.

McKee T B, Doesken N J and Kleist J 1993 The relationship of drought frequency and duration to time scales; In: Proceedings of the 8th Conference on Applied Climatology, Boston, MA, USA, Am. Meteorol. Soc. 17(22) 179-183.

McKee T B, Doesken N J and Kleist J 1995 Drought monitoring with multiple time scales, Preprints, 9th Conference on Applied Climatology, Dallas, TX, Am. Meteor. Soc., pp. 233-236.

MED WS and D WG 2007 Mediterranean Water Scarcity and Drought; Working Group: Technical report on water scarcity and drought management in the Mediterranean and the Water Framework Directive (Tec. Rep. 0092007). EUWI/WFD Joint process, April 2007. http:// www.emwis.net/topics/WaterScarcity. 
Michaelides S and Pashiardis S 2008 Monitoring drought in Cyprus during the 2007-2008 hydrometeorological year by using the standardized precipitation index (SPI); European Water Publ. 23/24 123-131.

Mishra A K and Singh V P 2010 A review of drought concepts; J. Hydrol. 391(1-2) 202-216.

Pashiardis S and Michaelides S 2008 Implementation of the standardized precipitation index (SPI) and the reconnaissance drought index (RDI) for regional drought assessment: A case study for Cyprus; European Water Publ. 23/24 57-65.

Ragab R and Hamdy A 2004 Water management strategies to combat drought in the semiarid regions; In: Water Management for Drought Mitigation in the Mediterranean, Centre International de Hautes Etudes Agronomiques Méditerranéennes (CIHEAM), Options Méditerranéennes, Série B, No. 47, p. 328.

Rossi G and Cancelliere A 2002 Early warning of drought: Development of a drought bulletin for Sicily; Proc. 2nd Int. Conf. "New Trends in Water and Environmental Engineering for Safety and Life: Eco-compatible Solutions for Aquatic Environments", Capri, Italy, June 24-28, 2002, pp. 1-12.
Saigh O 2005 Isotopic composition of precipitation from Algiers and Assekrem; IAEA-TECDOC-1453, pp. 5-18.

Smiatek G, Kaspar S and Kunstmann H 2013 Hydrological climate change impact analysis for the Figeh Spring near Damascus, Syria; J. Hydrometeor. 1 577-593.

Thom H C S 1966 Some methods of climatological analysis; WMO Technical Note No. 81, Secretariat of the World Meteorological Organization, Geneva, Switzerland, $53 \mathrm{p}$.

Turgu E 2008 Using standardized precipitation index for monitoring drought and analyzing drought; BALWOIS 2008 - Ohrid, Republic of Macedonia - 27, 31 May 2008.

United Nations 1982 Groundwater in Eastern Mediterranean and Western Asia; Natural Resources/Water Series $n^{\circ} 9$; United Nations: New York.

Vicente-Serrano S M, Gonzalez-Hidalgo J C, De Luis M and Raventos J 2004 Drought patterns in the Mediterranean area: The Valencia region (eastern Spain); Clim. Res. 26 $5-15$.

Wilhite D A and Glantz M H 1987 Understanding the drought phenomenon: The role of definition; In: Planning for Drought (eds) Wilhite D A, Eastrling W E and Wood D A, Vestview Press, Boulder, CO, pp. 11-27.

MS received 5 January 2016; revised 18 February 2016; accepted 27 February 2016

Corresponding editor: Subimal Ghosh 